\title{
Comment
}

\section{Educação Especial na perspectiva Inclusiva: Crianças com Transtorno do Espectro do Autismo}

\author{
Marcio Moreira da Silva ${ }^{l}$
}

\begin{abstract}
Resumo: A Educação Especial na Perspectiva da Educação Inclusiva preconiza o atendimento às pessoas com necessidades especiais no âmbito da escola regular. Pessoas com Transtornos do Espectro do Autismo apresentam desenvolvimento atípico estando englobadas dentro dos Transtornos Globais do Desenvolvimento. O objetivo deste estudo foi revisar criticamente a literatura a respeito dos TEA no âmbito da Educação Especial e Inclusiva. Acredita-se que a inclusão escolar possa proporcionar oportunidades ímpares para essas pessoas que se apresentam com dificuldades na interação social, comportamentos restritos e repetitivos e na comunicação.
\end{abstract}

Palavras Chave: Educação Especial. Educação inclusiva. Autismo.

\section{Special Education in Inclusive Perspective: Children with Spectrum Disorder}

\begin{abstract}
The Special Education Inclusive Education Perspective calls for care to people with special needs in the regular school. People with Autism Spectrum Disorders have atypical development being encompassed within the Pervasive Developmental Disorders. The aim of this study was to critically review the literature regarding the TEA under the Special and Inclusive Education. It is believed that the school inclusion can provide unique opportunities for those people who present with difficulties in social interaction, restricted and repetitive behaviors and communication.
\end{abstract}

Keywords: Special Education. Inclusive Education. Autism.

\section{Introdução}

A Educação Especial tem como objetivo atender de maneira especializada aquelas pessoas que são portadoras de necessidades especiais. Historicamente, há momentos em que essa categoria acontece à parte da sociedade em instituições, o que acabou por gerar segregação dessas pessoas. Com o avanço da Educação Inclusiva, essas pessoas podem ter acesso à escola regular, dentre elas as que se configuram dentro dos Transtornos Globais do Desenvolvimento, como é o caso dos Transtornos do Espectro Autista.

\footnotetext{
${ }^{1}$ Mestrando em Educação pela Unisullivan University. Bacharel em Psicologia pela UNILEÃO Centro Universitário. Especialista em Psicologia Aplicada à Educação pela Universidade Regional do Cariri (URCA). Endereço para correspondência: Rua Nossa Senhora do Carmo, 140, Franciscanos - CEP: 63020-180, Juazeiro do Norte -CE. E-mail: marciopsi@bol.com.br
} 
Como veremos posteriormente, não há um consenso do ponto de vista científico com conceitos fechados acerca do autismo, isso porque já houve várias definições sobre e estas ainda estão em processo, ocorrendo várias classificações de caráter técnico, como no caso do DSM$\mathrm{V}$, que vem sofrendo várias alterações ao longo dos anos.

No que se refere à educação, o presente trabalho trata da educação Especial na perspectiva da Educação Inclusiva, com ênfase nos Transtornos do Espectro Autista, a partir de agora apresentado pela sigla (TEA). Para isso faremos um breve percurso histórico sobre o conceito de autismo, trazendo seus principais pesquisadores, em seguida apresentando os critérios diagnósticos desenvolvidos pelos dois principais manuais de classificações de transtornos mentais o CID-10 e o DSM-V, esclarecendo alguns termos técnicos que vão surgindo com o tempo. De modo que se pode perceber que o campo de estudos sobre o autismo ainda está em desenvolvimento.

Justificamos a presente pesquisa científica pela relevância da Educação Especial e Inclusiva ser alvo de debates e de normas e legislações a nível mundial. Em nível nacional temos políticas públicas propostas pelo Ministério da Educação (MEC). Além da presença de crianças dentro dos TEA começarem a frequentar as escolas regulares, o que pode causar em alguns professores certa dificuldade, principalmente quando este não teve a oportunidade de formação docente acerca do tema.

Adotamos a pesquisa bibliográfica, que para Fonseca (2002) é desenvolvida a partir do levantamento de referências teóricas já analisadas, e publicadas através de meios escritos e eletrônicos, como livros, artigos científicos, páginas da internet.

\section{A educação Especial e a Educação Inclusiva}

De acordo com Brasil (2008) a Educação Especial refere-se a uma categoria que foi destinada a pessoas com algum tipo de deficiência física ou intelectual especializada. Esta já ligada a um conceito de normalidade e anormalidade, baseada no aspecto clínico-terapêutico com influência nos testes psicométricos. 
Segundo Stobäus e Mosquera (2004) a Educação Especial surge no final do século XVIII e início do XIX nos países escandinavos e América do Norte com a institucionalização de caráter assistencialista, de maneira que estas pessoas ficassem longe do contato das demais pessoas. No Brasil desde o Império existiram instituições como dos meninos cegos em 1854, a de surdos em 1857, o Instituto Pestalozzi destinada ao atendimento de crianças com deficiência mental em 1926, a Associação de Pais e Amigos dos Excepcionais (APAE) em 1954 (BRASIL, 2008).

Esse tipo de educação estava caracterizado pela segregação, visto que acontecia a parte em instituições especializadas. Somente a partir de 1960, começa a ser questionada essa maneira de educar, havendo uma luta para que essas crianças pudessem aprender junto às escolas regulares em salas comuns, de maneira a poder integrá-las. Assim, para Coll, Palacios e Marchesi (1995) é a partir do final dos anos 60 que entra o conceito de Necessidades Educativas Especiais com o objetivo de promover novos enfoques educativos para esse público.

Um grande marco em relação da Educação Especial para uma Educação Inclusiva se dá com a Declaração de Salamanca na Espanha no ano de 1994. De acordo com Stobäus e Mosquera (2004) a declaração define a escola inclusiva como aquela que independentemente das dificuldades ou diferenças agrega de forma que essas possam aprender juntas, considerando os ritmos da aprendizagem de cada um, por meio de um currículo apropriado, de estratégias de ensino próprias e com a parceria das comunidades.

Segundo Brasil (2010) no ano de 2006 a Organização das Nações Unidas (ONU) estabelece a convenção sobre os direitos das pessoas com deficiência, da qual o Brasil é signatário. Em 2008 é apresentada a Política Nacional de Educação Especial na perspectiva da Educação Inclusiva, definindo como público os alunos com deficiência, incluindo os transtornos globais do desenvolvimento e altas habilidades (superdotação). Nessa perspectiva a educação inclusiva propõe trabalho pedagógico na escola regular, e em certos casos mais necessários um atendimento educacional especializado (AEE) onde existem recursos e mediações específicas em relações às atividades pedagógicas.

Na Política Nacional da Educação Especial na Perspectiva da Educação Inclusiva há espaço para alunos com transtorno global do desenvolvimento o que inclui as pessoas com diagnóstico de TEA (BRASIL, 2008). Em 2012 é instituída Política Nacional de Proteção dos Direitos da Pessoa com TEA, a lei No 12.764. Neste documento são afirmados os critérios que 
constituem uma pessoa com TEA, recordando de que elas são consideradas pessoas com deficiência para efeitos legais. No documento afirma-se ainda que o direito à educação sem qualquer tipo de discriminação tendo como base a igualdade de oportunidades, de pleno acordo com os preceitos da Convenção Internacional sobre os Direitos da Pessoa com Deficiência.

No caso do TEA a criança deve ser incluída em classe comum, e em havendo a necessidade, tem o direito a um acompanhante especializado. Referindo-se às atividades de comunicação, interação social, locomoção, alimentação e cuidados pessoais, de acordo com o decreto $\mathrm{N}^{\mathrm{o}} 8.368$, de 2 de dezembro de 2014.

\section{Transtornos do Espectro do Autismo (TEA)}

Conceituar Autismo não é algo simples. Para tentarmos definir, recorreremos a mais em voga atualmente que é à da $\mathrm{APA}^{1}$ que conceitua o autismo como se tratando de uma severa deficiência relacionada ao desenvolvimento, surgindo nos três primeiros anos de vida, envolvendo deficiências na interação social e na comunicação tanto verbal como não verbal.

Em relação à etimologia da palavra, de acordo com os autores Lotufo (2012), MüllerGranzotto e Müller-Granzotto (2012) e Amy (2001) o termo vem do grego autós significando "si mesmo" ou "comportamento de voltar-se para si mesmo", um ensimesmamento psicótico.

No que diz respeito ao que seja de acordo com Baptista e Bosa (2007) o autismo já esteve em várias categorias como síndrome comportamental, neuropsiquiátrica e ou neuropsicológica, transtorno invasivo do desenvolvimento, transtorno global do desenvolvimento, transtorno abrangente do desenvolvimento, psicose infantil, etc. Na categoria de esquizofrenia e psicose infantil, apareceu nos principais manuais da Organização Mundial de Saúde (OMS), a Classificação de transtornos mentais e de comportamento da CID-10 e da American Psychiatric Association (APA), o Manual Diagnóstico e Estatístico de Transtornos Mentais (DSM-V), permanecendo durante um bom tempo, até chegarmos a recente classificação de TEA.

${ }^{1}$ Disponível em: http://www.ama.org.br/site/definicao.html. Acesso em: 15 de Julho de 2016. 
Do ponto de vista histórico há certa divergência em relação à data de criação do conceito de autismo, Roudinesco e Plon (1998) afirmam que foi criado em 1907, Lotufo (2012) segue essa data. Entretanto Belisário e Cunha (2010) falam em 1911. Os autores citados concordam que foi o médico psiquiatra suíço Eugen Bleuler, que cunhou o termo, designado para adultos com sérias dificuldades para interagir com outras pessoas e apresentando um severo isolamento, estando associada à esquizofrenia.

Leo Kanner médico austríaco, no ano de 1943, observou 11 crianças, (08 meninos e 03 meninas), identificando problemas em cinco áreas: relações sociais e afetivas, comunicação e linguagem, mudanças de ambiente e rotina, memória, e hipersensibilidade a estímulos. Começando assim os primeiros estudos sobre autismo. Em relação às relações afetivas e sociais percebia que elas ignoravam o que vinha do meio, na linguagem percebia mutismo em algumas crianças, em outras a ecolalia (repetição de palavras ou frases produzidas por alguém), forte resistência às mudanças, memorização surpreendente em relação a conteúdos sem sentido, e a hipersensibilidade em relação a barulhos e objetos (BELISÁRIO E CUNHA, 2010).

De acordo com Gadia (2006), no ano seguinte, em 1944 o médico de Viena, Hans Asperger através de estudos em clínica pediatra, percebeu quase os mesmos sintomas presentes nas crianças observadas por Kanner, com algumas diferenças, dentre elas a inteligência preservada e ausência de déficits na linguagem. Belisário e Cunha (2010) ainda enumera como diferenças encontradas a dificuldade no fixar o olhar nas relações interpessoais, o olhar periférico e breve, as estereotipias comportamentais em gestos e palavras, apresentando-se monótonas.

Em relação ao termo TEA, de acordo com Belisário e Cunha (2010), Baptista e Bosa (2007) a psiquiatra inglesa Lorna Wing e a psicóloga Judith Gould desenvolvem o conceito de espectro autista no ano de 1979, logo após em estudo perceberem dificuldades na socialização, imaginação e comunicação em crianças. O termo espectro apresenta-se como sinônimo de contínuo, não uma categoria única, isso porque os transtornos representam um contínuo de prejuízos com intensidades de graus que vão de leve a grave, afetados nas áreas da comunicação social, e padrões comportamentais restritivos e repetitivos.

Para Smith (2008) o autismo trata-se de um diagnóstico específico, que se encontra pertencente aos TEA. Até o DSM-IV esses envolviam a síndrome de Rett, transtorno desintegrativo da infância, e o transtorno invasivo ou global do desenvolvimento não 
especificado de maneira separada. Na nova versão, o DSM-V fez uma fusão desses transtornos, pelo fato dos sintomas desses, representarem um contínuo de prejuízos, que são classificados de leve a grave em domínios da comunicação e de comportamentos restritivos e repetitivos. Com isso engloba todos os cinco diagnósticos que antes constavam na versão anterior.

A partir do DSM-V aparece uma nova estrutura dos sintomas. O que antes no DSM- IV aparecia como uma tríade de sintomas que trazia os déficits de comunicação separados pelos de prejuízos sociais e incluindo a área da linguagem, comunicação e imaginação, foi reduzida por uma díade compostas por déficits de comunicação social e comportamentos restritos e repetitivos (Tabela 1 ).

Considera-se o fato de que o atraso na linguagem não é característica única dos TEA e nem exclusivas dentro destes. Podem ser entendidos como fatores que possam influenciar nos sintomas clínicos, mas não como critérios diagnósticos de autismo nesses transtornos.

Tabela 1. Critérios diagnósticos do DSM-V para transtorno autista (2014)

\section{A. Déficits persistentes no que se refere comunicação social e nas interações sociais, manifestando-se por:}

1. Falta de reciprocidade socioemocional, havendo dificuldade em iniciar ou manter interações sociais;

2. Comunicação verbal e não verbal deficitária com pouca integração, incluindo ausência das expressões faciais próprias da comunicação não verbal;

3. Déficit no desenvolvimento, manutenção e compreensão dos relacionamentos, havendo ausência de interesse pelos pares.

\section{B. Padrões comportamentais restritos e repetitivos, interesses e atividades, manifestando-se por:}

1. Comportamentos motores ou verbais estereotipados, ou repetitivos, como alinhar ou girar objetos. Ecolalia ou frases idiossincráticas;

2. Rotinas ritualizadas de comportamentos verbais ou não verbais. Dificuldades às mudanças, e insistência nas mesmas coisas;

3. Interesses restritos e fixados a objetos incomuns;

4. Estímulo aumentado sensorialmente, como interesse por luzes ou movimento, tocar ou cheirar objetos excessivamente.

*Adaptado do DSM-V 
Os sintomas aparecem precocemente no período do desenvolvimento, embora só sendo manifestos no momento em que as demandas sociais excedam os limites das capacidades, ou estejam encobertos por alguma estratégia aprendia posteriormente na vida. Além de causarem prejuízo social e profissional e ou em outras áreas importantes da vida.

Foi também incluso no DSM V o nível de gravidade referentes aos critérios A e B, sendo do nível 1 (exigindo apoio), 2 (exigindo apoio substancial) e 3 (exigindo muito apoio substancial), indicando leve, moderado e grave respectivamente, indo de interferência significativa nessas áreas, a dificuldades, até dificuldades extremas. Isso é importante porque todas as pessoas com TEA não são iguais em seus sintomas, ou comprometidas em todas as áreas. Algumas apresentarão determinados comprometimentos, enquanto outras não.

\section{TEA e Educação Inclusiva}

Belisário e Cunha (2010) afirmam que a entrada na escola dessas crianças é um desafio tanto para elas devido a essas dificuldades, como a inflexibilidade, ambiente, assim como para os professores que se deparam com uma experiência nova geralmente cheia de sentimentos de impotência e angústia.

Isso fica claro, considerando-se que as pessoas diagnosticadas com TEA caracterizamse como um desafio para a educação, visto que algumas crianças com esses transtornos possuem dificuldades no campo das relações sociais e comportamentais, sendo que algumas apresentam dificuldades na linguagem. Isso considerando o fato de que na escola a linguagem falada e a não verbal fazem parte do aprendizado, assim como a socialização.

Riesgo (2016), afirma que as áreas como linguagem, relacionamento interpessoal além do foco de interesse são prejuízos precoces que afetam diretamente o aprendizado. $\mathrm{O}$ fato é que as crianças que tem diagnóstico de TEA possuem diferentes graus de comprometimento. Algumas com retardo mental terão o aprendizado geralmente mais prejudicado. Por isso, o DSM-V trabalha com as categorias de graus que vão de leve a grave dependendo do comprometimento. 
Portanto é muito importante que a criança possa ter acesso a escola logo quando pequena na educação infantil de maneira que essa possa ser estimulada precocemente com estímulos físicos, emocionais, cognitivos, psicomotores e sociais (BRASIL, 2008).

Hoje existem diversas maneiras de estruturar o ensino de crianças com TEA. Segundo Smith (2008) os programas educacionais nos Estados Unidos geralmente envolvem instruções em habilidade sociais. Essas contêm metas e objetivos específicos para o desenvolvimento da aprendizagem da empatia, de fazer e manter amizades e ainda se adequar a comportamentos sociais diversos. Em relação à linguagem são utilizadas ferramentas tecnológicas, isto porque crianças com TEA conseguem lidar com a tecnologia de maneira fácil sem necessariamente precisarem de apoio.

Crianças dentro do espectro autista geralmente precisam de apoios visuais e o Sistema de Comunicação por troca de figuras (PECS - Picture Exchange Comunication System), trabalha justamente o aprendizado da comunicação, principalmente aquelas que têm déficits na comunicação verbal. Esse sistema representa por meio de figuras categorias como roupas, brinquedos, atividades, sentimentos, etc.

É oportuno o que nos diz Mantoan (2008, p.85):

\begin{abstract}
Ao receber uma criança com autismo, evidencia-se a impossibilidade de atuarmos sob a lógica da prontidão de objetivos e planejamentos pré-concebidos, com a organização de espaços e tempos rígidos. Faz-se necessário investir tempo no conhecimento desse aluno através do cotidiano escolar para que se possa estabelecer estratégias pedagógicas e reconhecer as possibilidades de aprendizado (MANTOAN, 2008, p.85).
\end{abstract}

Dessa maneira urge uma formação de docentes que esteja preparada para acolher essas crianças de maneira que possa favorecer o processo de inclusão além da aprendizagem das crianças na escola. Conhecer a criança é ir além das categorias diagnósticas, não apenas com um olhar fixado nas dificuldades que ela possa apresentar, mas, sobretudo conhecer as suas capacidades existentes.

Conhecer sobre o TEA e suas características e possíveis ações pedagógicas pertinentes é de suma importância, principalmente para desfazer quaisquer preconceitos com as crianças com TEA. Citamos no Brasil o caso do Rio de Janeiro que através do Instituto Municipal Helena Antipoff (IHA) lançou em 2011 um documento com que inclui orientações para inclusão de alunos com Transtornos Globais do Desenvolvimento, no qual o TEA faz parte. Organizado 
por Taveira (2011), o documento disponibiliza intervenções no que diz respeito às situações que envolvem as interações sociais, comunicação e comportamento.

Em relação à formação de professores, pode-se citar o Programa de Formação Continuada de Professores em Educação Especial (Renafor) cujo objetivo é contribuir para a qualidade da educação de forma continuada para a formação docente, nas modalidades presenciais e à distância. Outro exemplo é o Programa Educação Inclusiva: Direito à Diversidade que foi criado em 2003.

\section{Considerações finais}

A educação Especial na perspectiva da Educação Inclusiva é de suma importância para pessoas com Transtornos do Espectro do Autismo. Para tanto se faz necessário uma formação contínua de professores acerca da temática, de maneira a poder incluir e proporcionar o aprendizado desde a educação infantil, perpassando pelos outros graus do ensino, como fundamental, médio e superior.

Essa formação de professores deve ser adequada, que favoreça uma competência técnica e afetiva. Assim, a entrada de alunos com TEA também requer mudanças e reflexões referentes aos modelos de ensinar baseados geralmente num pedagogia tradicional.

Apesar das dificuldades apresentadas por algumas pessoas com TEA, estas devem ser acolhidas e lhe dado o direito de estarem nas escolas regulares, assim como o direito ao aprendizado de maneira especializada.

Espera-se que esse trabalho, possa contribuir com a ampliação da produção de conhecimentos e reflexões acerca da temática, despertando o desejo de aprofundamento, no âmbito educacional.

\section{Referências}

AMERICAN PSYCHIATRIC ASSOCIATION (APA). Manual diagnóstico e estatístico de transtornos mentais (DSM-V) Tradução de Maria Inês Correa Nascimento et al; revisão técnica Aristides Volpato Cordiolo. 5 ${ }^{\mathrm{a}}$ ed. Porto Alegre: Artmed, 2014. 
AMY, Marie. Enfrentando o autismo: a criança autista, seus pais e a relação terapêutica. Tradução: Sérgio Tolipan. Rio de Janeiro. Jorge Zahar editores, 2001.

BAPTISTA, Claudio; BOSA, Cleonice. Autismo e educação: reflexões e propostas de intervenção. Porto Alegre: Artmed, 2007.

BELISÁRIO, Filho; CUNHA, Patrícia. A Educação Especial na Perspectiva da Inclusão Escolar: transtornos globais do desenvolvimento. Brasília: Ministério da Educação, Secretaria de Educação Especial: [Fortaleza]: Universidade Federal do Ceará, 2010. v. 9. (Coleção A Educação Especial na Perspectiva da Inclusão Escolar)

BRASIL. Ministério da Educação. Secretária de Educação Especial. Política Nacional de Educação Especial na perspectiva da Educação inclusiva. Brasília: MEC, 2008.

Ministério da Educação. Secretária de Educação Especial. Marcos Políticos-Legais da Educação Especial na Perspectiva da Educação Inclusiva. Brasília: MEC, 2010.

COLL, César; MARCHESI, Álvaro; PALÁCIOS, Jesus. Desenvolvimento psicológico e educação. Transtornos do desenvolvimento e necessidades educativas especiais. Volume 3. $2^{\mathrm{a}}$ edição. Porto Alegre: Artmed, 2004.

FONSECA, João José Saraiva. Metodologia da Pesquisa Científica. Curso de especialização em comunidades virtuais de aprendizagem - Informática educativa. UECE - Universidade Estadual do Ceará (Centro de educação). Disponível em: http://www.ia.ufrrj.br/ppgea/conteudo/conteudo-2012-1/1SF/Sandra/apostilaMetodologia.pdf. Acesso em: 21 jul.2016.

GADIA, C. Aprendizagem e autismo. In ROTTA, Newra; OHLWEILER, Lygia; RIESGO, Rudimar. Transtornos da aprendizagem: abordagem neurobiológica e multidisciplinar. $2^{\mathrm{a}}$ edição. Porto Alegre: Artmed, 2016.

LOTUFO, Larissa. Desmistificando as cores do autismo. Trabalho de conclusão de curso apresentado curso de comunicação social/jornalismo como requisito mínimo para a obtenção do título de bacharel em jornalismo. Bauru, 2012.

MANTOAN, Maria. O desafio das diferenças nas escolas. Editora Vozes, Petrópolis, RJ. 2008.

MÜLLER-GRANZOTTO, Marcos; MÜLLER-GRANZOTTO, Lorena. Psicose e sofrimento. São Paulo: Summus, 2012.

ORGANIZAÇÃO MUNDIAL DA SAÚDE (OMS). Classificação de transtornos mentais e de comportamento da CID-10: descrições clínicas e diretrizes diagnósticas. Porto Alegre: Artes Médicas: 1993. 
ROUDINESCO, Elisabeth; PLON, Michel. Dicionário de Psicanálise. Tradução: Vera Ribeiro, Lucy Magalhães. Supervisão da edição brasileira: Marco Antonio Coutinho Jorge. Rio de Janeiro: Zahar, 1998.

RIESGO, Rudimar. Introdução à aprendizagem e situações específicas. In ROTTA, Newra; OHLWEILER, Lygia; RIESGO, Rudimar. Transtornos da aprendizagem: abordagem neurobiológica e multidisciplinar. $2^{\mathrm{a}}$ edição. Porto Alegre: Artmed, 2016.

SMITH, Deborah. Introdução à Educação Especial. Ensinar em tempos de inclusão. Artmed, 2008.

STOBÄUS, Claus; MOSQUERA, Juan. Educação especial: em direção à educação inclusiva. $2^{a}$ edição. EDIPUCRS. Porto Alegre, 2004.

TAVEIRA, Cristiane. Orientações para inclusão de alunos nas escolas do município do Rio de Janeiro - Rio de Janeiro, RJ: Secretaria Municipal de Educação, 2011. Disponível em: $<$ https://ihainforma.files.wordpress.com/.../coletc3a2nea-de-textos-iha-2011.pdf >. Acesso em: 20 jul.2016.

Como citar este artigo (Formato ABNT):

SILVA, Marcio M. Educação Especial na perspectiva Inclusiva: Crianças com Transtorno do Espectro do Autismo. Id on Line Revista Multidisciplinar e de Psicologia, Abril de 2017, vol.11, n.35, p.56-66. ISSN: 1981-1179.

Recebido: 10.05 .2017

Aceito: .18.05.2017 